Cad. Est. Ling., Campinas, 46(1):21-42, Jan./Jun. 2004

\title{
O PRIMEIRO DICIONÁRIO MÉDICO DO BRASIL
}

\author{
LÍDIA ALMEIDA BARROS \\ (UNESP)
}

\begin{abstract}
RESUMO Cet article constitue l'un des premiers résultats de notre recherche au sein du projet Histoire des dictionnaires de Médecine du Brésil. Nous croyons avoir identifié le premier répertoire lexicographique de Médecine élaboré par un brésilien et «publié » dans notre pays. Dans cet article nous présenterons des données historiques à propos de l'oeuvre et son auteur; nous procéderons à une analyse de l'organisation interne de l'ouvrage d'un point de vue lexicographique, et montrerons comment ce livret, daté du XVIIe siècle, est toujours respecté par les scientifiques et attire encore l'intérêt de la Médecine de nos temps.
\end{abstract}

\section{INTRODUÇÃO}

Qualquer afirmação categórica sobre dados históricos é temerária. Toda verdade científica é passível de revisão à luz de novas descobertas. Nesse sentido, podemos apenas afirmar que, em nossa pesquisa sobre o tema "História dos dicionários médicos no Brasil", encontramos um trabalho que é forte candidato à indicação de primeiro dicionário dessa área do saber elaborado em nosso país. Trata-se de uma pequena obra com título longo: Nomes das partes do corpo humano, pella lingua do Brasil, cõ primeiras, segundas \& terceiras pessoas \& mais differenças q nelles ha; mujto necessarios aos confessores que se occupão no menisterio de ouuir confissões, \& ajudar aos jndios onde de contino seru? Juntos por ordem alphabetica, pera mais facilmente se achar?, \& saber?; pello padre PERO de CASTILHO da Companhia de Iesu. Anno 1613.

Essa obra é considerada por autoridades médicas como a primeira Nomina Anatômica ${ }^{1}$ brasileira e, pela forma de organização das informações, também pode ser considerada como o primeiro dicionário brasileiro de Anatomia Humana, a mais antiga e tradicional das área da Medicina.

\section{COMO A OBRA CHEGOU AOS BRASILEIROS DO SÉCULO XX}

Adquiridos pelo bibliófilo Felix Pacheco em Paris, este vendeu, tempos mais tarde, à Prefeitura de São Paulo, manuscritos do século XVII compostos de duas obras: um

${ }^{1}$ Nomina Anotomica, documento que oficializa o conjunto de termos que designam as estruturas do corpo humano. 
BARROS - O primeiro dicionário médico...

Vocabulario na lingua brasílica (dicionário manuscrito português-tupi) e, em anexo a esse, os Nomes das partes do corpo... O material foi entregue ao Chefe da Divisão de Bibliotecas do Município, que, na época, era Rubens Borba de Morais, famoso por sua paixão e cuidados com o acervo.

Em 1936, os textos originais da obra do jesuíta foram entregues a Plínio Ayrosa, primeiro professor de tupi da Universidade de São Paulo, que, após estudá-los com cuidado, organizou a publicação da obra em 1937, pela Empresa Gráfica da Revista dos Tribunais, de São Paulo, da qual só foram impressos "cinqüenta exemplares em papel especial" (Ayrosa, 1937, contra-capa). O Vocabulario na lingua brasílica foi editado, sob a coordenação de Ayrosa, pelo Departamento de Cultura do Município de São Paulo, em 1938.

De acordo com esse pesquisador, a obra adquirida por Félix Pacheco em Paris (Vocabulário + Nomes das partes do corpo...) tem origem comum com a parcialmente copiada por Ferreira França de um exemplar manuscrito que se encontra no Museu Britânico, em Londres, e integra o "Catálogo dos Manuscritos Portugueses" dessa instituição. Esse trabalho foi publicado em 1859 como parte da coletânea organizada por França, Chrestomathia da Lingua Brasílica. Não fica claro, no entanto, se os Nomes das partes do corpo... faziam parte do mesmo manuscrito do Vocabulário. Ayrosa acredita ser possível que essas duas obras se encontrassem juntas no documento original, uma vez que se assemelham em muito às obtidas por Félix Pacheco (Ayrosa, 1937, p. 16).

\section{DÚVIDAS SOBRE A AUTORIA DA OBRA}

O estudo minucioso a que procedeu Plínio Ayrosa sobre os Nomes das partes do corpo... deixou-o intrigado sobre divergências evidentes de grafia quando comparada a primeira parte do dicionário com a segunda:

Quem quer que examine com alguma atenção os manuscritos notará, sem dificuldade alguma, que há enormes diferencias ortográficas entre a primeira e a segunda parte; que várias palavras existentes numa delas não aparecem na outra e, finalmente, que termos portugueses surgem aqui e ali escritos de maneira diversa.

Ora, parece-nos, só as diverências ortográficas dos termos tupis e portugueses que ocorrem nas duas partes em que se divide tão pequenino trabalho, são de molde a afastar a possibilidade de ter ele sido escrito por pessoa culta e dada aos estudos como o foi Pero de Castilho. ...

Pero de Castilho, si tivesse escrito ele mesmo, com seu próprio punho, estes documentos, teria forçosamente usado de apenas um sistema ortográfico, maximé no registro de vocábulos tupiguaranis. (Ayrosa, 1937, p. 12)

O autor dá como provas de suas suspeitas elementos que evidenciam dois sistemas ortográficos diversos para a transcrição, em português, de sons do tupi. De acordo com o pesquisador, a primeira parte deve ter sido escrita por uma pessoa, que adotou certos critérios, e a segunda por outra, que pode ter-se baseado na grafia empregada por Anchieta em sua Arte de Gramática da língua mais usada na costa do Brasil, publicada em 1595. As conclusões de Ayrosa vão ainda mais longe: 
Verificada a identidade quase completa de ambos e perfeitamente constatados os erros, a péssima grafia dos termos tupis e a inépcia de quem os acentuou, queremos concluir que nem o nosso manuscrito e menos o de Ferreira França podem ser atribuídos ao punho de Pero de Castilho; ambos foram mal copiados por alguém que teve à vista o texto original do prestadio jesuíta ou, talvez mesmo, uma cópia já de seu trabalho. (Ayrosa, 1937, p. 17)

A hipótese lançada pelo pesquisador tem seu fundamento, uma vez que esse tipo de problema tem, ao longo da história das obras que antecedem a invenção da imprensa, inúmeros precedentes de cópias que deturpavam os originais.

Outro detalhe não passou despercebido a Ayrosa: o Vocabulário na Língua Brasílica (Portuguez-Brasiliano), que acompanha, nos manuscritos, os Nomes das partes do corpo..., foi copiado em 1622. Esse dado leva-o a lançar a hipótese de que os o pequeno dicionário de Anatomia tenha sido escrito na Bahia ou Pernambuco, mas tenha sido rapidamente copiado em vários exemplares e enviado a diversas localidades do Brasil da época. $\mathrm{Na}$ Província de Piratininga (São Paulo), foi enriquecido, em 1622, com uma lista inversa, na qual a língua de partida era o português e a de chegada, o tupi. Essa é a opinião de Ayrosa, mas a polêmica não se esgotou aí:

Muitos manuscritos são analisados e comparados, procurando-se identificar os autores e avalia-los. O VLB é um exemplo. Na discussão sobre sua autoria, que se estende pelas décadas de 30 e 40, envolveram-se, além de Plínio Ayrosa e outros estudiosos do tupi, o padre Serafim Leite, que então escrevia sua História da Companhia de Jesus no Brasil e tinha acesso aos arquivos da Companhia. Buscava-se indicar entre os primeiros jesuítas que estudaram o tupi os que teriam composto os manuscritos. Depois de se cogitar o nome de Pero de Castilho, Leite $(1944,1946)$ aponta Leonardo do Vale como autor do VLB. Enquanto isso, Maria de L. de P. Martins, analisando manuscritos do VLB, do DPB e do DBP, tende para a autoria de Anchieta. A questão não ficou resolvida, mas o que importa é sublinhar o trabalho com a historicidade dos textos, que ultrapassava o interesse biográfico e se estendia à análise dos fatos de linguagem. (Nunes, 1996, p. 129-130)

Embora não se possa determinar com precisão a autoria do VLB e nem se saiba ao certo se os Nomes das partes do corpo... pertençam, como anexo, a essa obra, sobre a autoria destes últimos parece não pairar dúvidas: é de Pero de Castillo, pelo menos em sua parte inicial tupi-português.

\section{SOBRE PERO DE CASTILHO}

São poucos os dados biográficos sobre esse sacerdote brasileiro. A melhor fonte de informações continua sendo a carta do Padre Serafim Leite, enviada a Félix Pacheco, cujos trechos mais importantes foram transcritos por Ayrosa, na qual pode-se ler:

O P. Pero de Castilho é natural da Vila do Espírito Santo, onde nasceu em 1572. Entrou na Companhia de Jesus, na Baía, em 1587, com 15 anos de idade. Estudou gramática durante quatro anos e teologia moral por algum tempo. Em 1606 já era sacerdote, e em 1608 fez os últimos votos de Coajutor Espiritual. Foi Superior dalgumas Aldeias de índios (era-o em 1616 da aldeia de São João Baptista, anexa ao Colégio da Baía). Fez duas grandes entradas ao Sertão; uma em 1613 ao Rio Grande; outra em 1621 ao interior da Baía com o Padre José da Costa, siciliano. Da sua primeira missão deixou uma preciosa narrativa, dirigida ao P. Henrique Gomes, Provincial do Brasil, e escrita 
BARROS - O primeiro dicionário médico...

em Pernambuco, a 10 de maio de 1614, em português, intitulada Redação da Missão do Rio Grande: 1613-1614. Possuo cópia fotográfica dessa narração, ainda inédita. O P. Pero de Castilho dominava perfeitamente a língua brasílica, que aprendeu na meninice. Ainda vivia em 1631 no Colégio de

Pernambuco, com 59 anos de idade e boa saúde. (Ayrosa, 1937, p.22)

Essas são as informações que se tem do padre brasileiro nascido na Vila do Espírito Santo (diocese do Rio de Janeiro), que nos legou o primeiro dicionário médico do Brasil.

\section{CARACTERÍSTICAS LEXICOGRÁFICAS DA OBRA}

\section{ObJETIVOS E PúBLICO-ALVo}

Os Nomes das partes do corpo... não visavam auxiliar os médicos da época em seu trabalho de socorro aos índios. Seu objetivo primeiro era facilitar aos padres o ofício de catequese e, como se pode ler no título, ser um instrumento de utilidade "aos confessores que se occupão no menisterio de ouuir confissões, \& ajudar aos jndios onde decontino ser?". Seu público-alvo era, portanto, os sacerdotes que lidavam diretamente com as populações indígenas e sua motivação era de cunho religioso.

\section{A macroestrutura}

Na edição de 1937, antecede o dicionário propriamente dito um longo prefácio em que Plínio Ayrosa expõe seu conteúdo, objetivos e, principalmente, lança hipóteses sobre a história da obra. Complementa o livreto uma série de 249 notas explicativas sobre qiestões fonéticas, fonológicas, ortográficas e semânticas. O dicionário organiza-se em duas listas bilíngües, em ordem alfabética, de termos que designam estruturas da Anatomia Humana: a primeira, tupi-português; a segunda, na direção inversa.

As primeiras páginas de ambas as partes desse repertório lexicográfico apresentam os dados datilografados, acompanhados dos mesmos escritos pelo punho do autor. Para termos uma visão mais concreta da configuração da obra em si, vejamos algumas de suas páginas: 


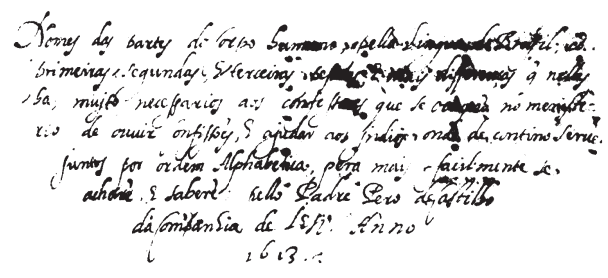

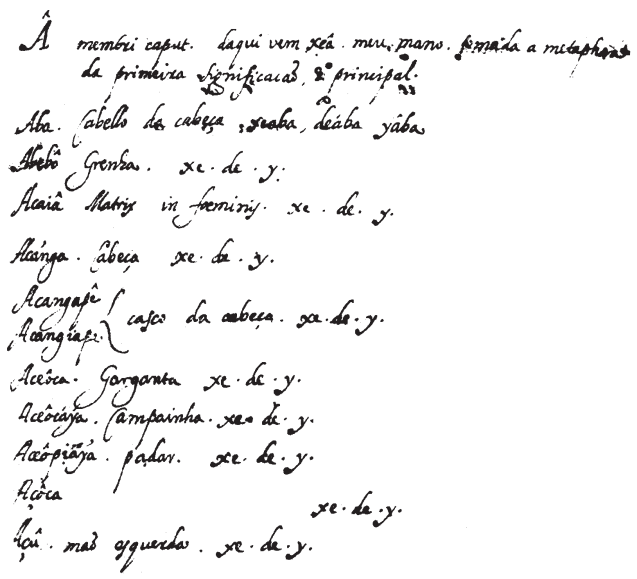

NOMES DAS PARTES DO CORPO HUMANO, PELla LINGUa do BRASIL, Có PRIMEIRAS, SEGUNDAS, \& TERCEIRAS PESSOAS \& MAIS DIFFERENÇAS N NELLES HA; MUJTO NECESSARIOS AOS CONFESSORES QUE SE OCCUPÃO NO MENISTERIO DE OUUIR CONFISSб̃ES, \& AJUDAR AOS JNDIOS ONDE DE CONTINO SERUẼ. JUNTOS POR ORDEM AL. PHABETICA, PERA MAIS FACILMENTE SE ACHARẼ, \& SABERẼ; PELlo PADRE PERO DE CASTILHO DA COMPANHIA DE IESU. ANNO 1613.

A

$1 \hat{A}$ membri caput. daqui vem $x e \hat{a}$. meu mano. tomada a metaphora da primeira significação, e principal.

2 Ába. Cabello da cabeça xeába, deába, yába.

3 Abebô. Grenha. xe. de. y.

4 Acaiâ. Matrix in fœminis. xe. de. y.

\section{[27]}

Figura 1: Pero de Castillo: Primeira página da parte tupo-português.

NOMES DAS PARTES DO CORPO HUMANO

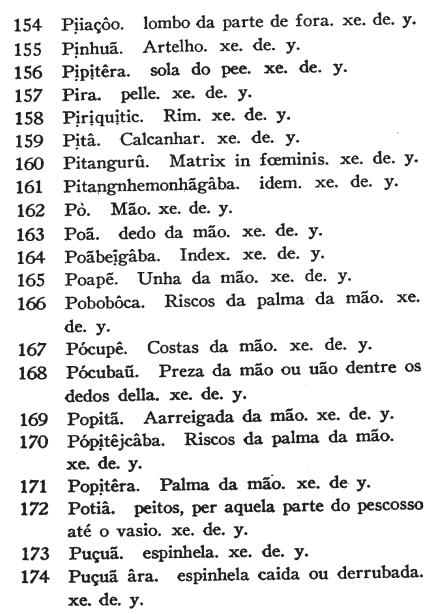
[ 36 ]
NOMES DAS PARTES DO CORPO HUMANO

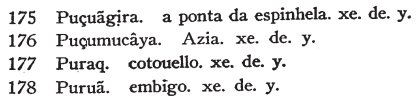

179 Sâba. pello. ou cabello do corpo. xe. de. c. 180 Sibâ. testa. xe. de. $y$.

181 Tacapê. o espaço que ha do embigo até a ventrecha, ou aquella parte assi chamada. xe. de. c.

182 Tacapeâba. os cabellos daquella parte. xe. de. c.

183 Tacô. uirilha. xe. de. c.

184 Tacoâba. pubes in forminis. xe. de. c.

185 Tacoaýa. genitale viri. xe. de. de. c.

186 Tacoayipitã. arreigado delle. xe. de. c.

187 Tacoayipitâ âba. pubes in maribus. xe. de. c.

188 Tay........ xe. de. c. (riscado no original.)

189 Táya. dentes. xe. de. c.

190 Taibâra. dentes enfrestados. xe. de. c.

191 Taibira. Gengiuas. xe. de. c.

[ 37 ]

Figura 2: Pero de Castillo: separação das entradas pelas letras do alfabeto. 
NOMES DAS PARTES DO CORPO HUMANO

235 Tịbịtâba. Sobrancelhas. xe. de. y.

236 Tịuê. barriga. o interior. xe. de. c.

237 Tịguêguaçú. bucho. xe. de. c.

238 Tiguê poî. tripas. xe. de c.

239 Tịmã. perna. xe. de. c.

240 Tịmãoô. barriga da perna. xe. de. c.

241 Tịurû. bexiga. xe. de. $y$.

242 Tô. Carne humana. xe. de. c.

243 Tobâ. Rosto humano. xe. de. c.

Tobâpiâba.

244 Tobâapoã.

Tobâibíra. topete. xe. de. c.

Tobâapịnra.

245 Tobapi. entradas. xe. de. c.

246 Tobaguâ. idem. xe. de. c.

247 Topê. capella dos olhos. xe. de. c.

248 Topeâba. pestanas. xe. de. c.

249 Topepira. capella dos olhos. c.

250 Tiguị. sangue humano. xe. de. c.

251 Tumbị. Cadeiras. xe. de. c.

252 Tumbịquịra. Rabadilha. xe. de. c.

\section{U}

253 Oba. coxa da parte dianteira. xe. de. y.

[ 40 ]
NOMES DAS PARTES DO CORPO HUMANO

254 Obba poã. a ponta da coxa junto ao giolho. xe. de. y.

255 Ơba poã aị́a. lagarto. xe. de. y

256 Óbipi. Arreigada da coxa junto a virilha. xe. de. $y$.

257 Uûba. Genitale viri. E ainda que metaphorico he usado. xe. de. c.

Finis

Figura 3: Pero de Castillo: Última página da primeira parte.

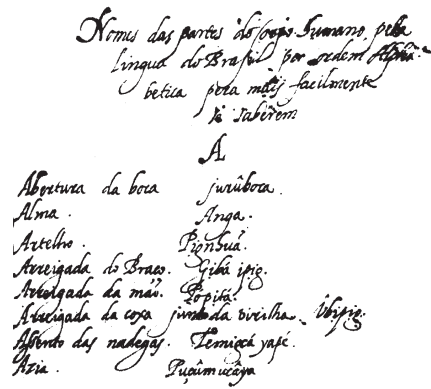

क

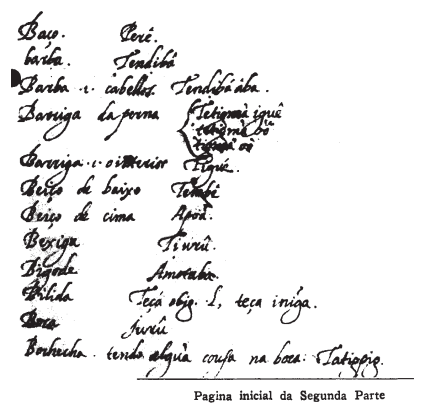

NOMES DAS PARTES DO CORPO HUMANO, PELLA LINGUA DO BRASIL POR ORDEM ALPHABETICA PERA MAIS FACILMENTE SE SABEREM.

258 Abertura da boca. jurûboca.

259 Alma. Anga

260 Artelho. Pignhuä.

261 Arreigada do Braço. Gịbá ipig.

262 Arreigado da mão. Pópịtá.

263 Arreigado da coxa junto da virilha. Obipig.

264 Assento das nadegas. Temigcá yapé.

265 Azia. Puçûmucâya.

B

266 Baço. Perê.

267 Barba. Tendibâ.

268 Barba. i. cabellos. Tendịaâba.

269 Barriga da perna. $\left\{\begin{array}{l}\text { Tetigmã iguê } \\ \text { Tetigmã oô. } \\ \text { Tigmã oô. }\end{array}\right.$

[45]

Figura 4: Pero de Castillo: Primeira página da segunda parte (português-tupi). 


\section{NOMES DAS PARTES DO CORPO HUMANO}

V
429 Vão das costellas da pte debaixo. Arucan-
guîra.

430 Vão dentre os dentes. Tainhobaú.

431 Vasio. Iquépuba.

432 Vea. Taijca.

433 Ventrecha. Tambe.

434 Ventre. Igbịguâ.

435 Ventas. Apijgyã.

436 Vesgo. Teçâbanga.

437 Virilha. Tacô.

438 Vnhas dos dedos dos pes. Mị̄apé.

439 Vnhas dos dedos da mão. Moãpê.

Frais Laus Deo Virginig.

Figura 5: Pero de Castillo: Última página da segunda parte (português-tupi).

Assim, da página 27 à 41 dispõem-se as entradas de acordo com a letra do alfabeto que inicia a entrada em língua indígena, uma vez que a primeira parte é a tupi-português. Os verbetes são precedidos de um número de série. No total, são 257. A segunda parte inicia-se na página 45 e vai até à 54. A mesma organização dos verbetes lhe é dada, desta feita na ordem português-tupi. Os números de série dão continuidade à seqüência, ou seja, iniciam-se em 258 e o último verbete é de número 439, perfazendo, assim, 181 termos.

Evidencia-se, portanto, uma defasagem entre o tratamento dado à nomenclatura nas duas partes da obra: a tupi-português possui 76 verbetes a mais que a outra. Uma possível explicação para essa situação seria a suspeita de que a versão português-tupi não seja produto de um mesmo autor. No que concerne à organização da lista de entradas, não há, assim, homogeneidade no tratamento da nomenclatura no interior do conjunto da obra. 


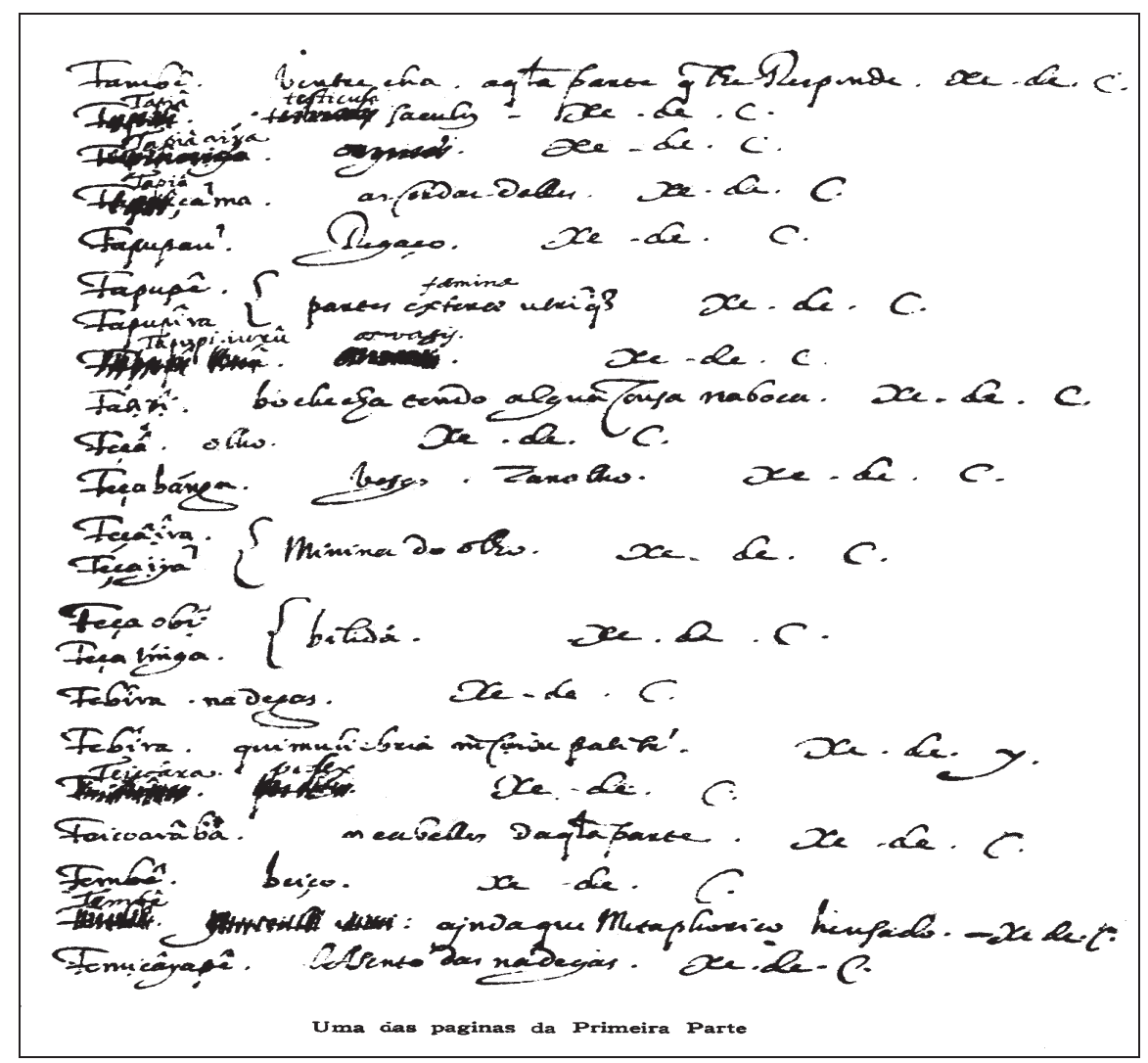

Figura 6: Pero de Castillo. Rasuras manuscritas.

Aqui encontramos certas entradas em tupi (LP) e/sou seus equivalentes rasurados. Os curadores da edição de 1937 registram esse fato sob a forma de uma observação entre parênteses, ao final do enunciado lexicográfico dos respectivos verbetes, como se pode observar em:

94. Ibiguâ. Ventre. xe. de. y. (riscado no original) (Ayrosa, 1937, p. 32)

95. Ibiguapîra. xe. de. y. (riscado no original) (Ayrosa, 1937, p. 32)

188. Tay ............ xe. de. c. (riscado no original) (Ayrosa, 1937, p. 37)

Como podemos ver, no lugar dos termos que não puderam ser identificados, os organizadores da publicação preencheram o espaço com uma série de pontinhos. Apesar do obstáculo à compreensão provocado pelas rasuras, alguns termos puderam ser identificados, como é o caso de podex, correspondente, em português, de teicoâra, (na página original manuscrita), e de ibiguâ. (ventre), mas outros não, como no caso dos verbetes 95 e 188 e, na página manuscrita, tapiâaiýa. Nenhuma explicação é dada sobre os possíveis motivos desse procedimento. Uma hipótese seria a incerteza, por parte de 
Cadernos de Estudos Lingüísticos 46(1) - Jan./Jun. 2004

Castillo, sobre os termos em tupi e/ou seu equivalente, em português, mas não há elementos que nos permitam fazer qualquer afirmação categórica.

\title{
A microesturura
}

O programa básico de informações que se observa nos verbetes é composto dos seguintes microparadigmas: entrada em língua de partida (LP) e seu equivalente em língua de chegada (LC). Além desses dados, encontramos, na primeira parte da obra, outros como xe. de. y. ou xe. de. c. A explicação sobre a identidade e função desses elementos vem com Ayrosa:

No nosso manuscrito vem, além das palavras tupis, os pronomes ou índices de possessão das três primeiras pessoas do singular, isto é, $x e$. de. $y$. ou $c$. Isso demonstra uma preocupação muito particular do autor do trabalho, um como que traço característico numa obrinha que, por suas finalidades, poderia ter exigido muito mais úteis e interessantes anotações. (Ayrosa, 1937, p. 16)

A presença desses dados nos enunciados lexicográficos dos verbetes já é pré-anunciada no próprio título da obra: Nomes das partes do corpo humano, pella lingua do Brasil, c $\tilde{\boldsymbol{\sigma}}$ primeiras, segundas \& terceiras pessoas.

O sintagma grifado indica os dados que se observam nos verbetes logo após o equivalente em português. Esses se encontram, todavia, apenas na primeira parte do repertório, não constando dos enunciados lexicográficos da segunda. Esse seria, talvez, mais um indício de que o trabalho completo foi feito a quatro mãos (ou mais), provavelmente em épocas diferentes. Em outras palavras, esse detalhe pode reforçar a idéia de que não tenha sido a mesma pessoa a preparar as listas tupi-português e português-tupi.

Outro aspecto que chama a atenção é a indicação de sinonímia. De fato, tanto na parte tupi-português, quanto na outra, por vezes ocorrem situações em que para dois ou mais termos em uma língua seja indicado apenas um equivalente na outra. É o caso, por exemplo, dos verbetes 6, 7, 244 e 269.

\section{Acangapê}

7. Acangiape

\section{Tobâpiába \\ Tobâapoã \\ Tobâibíra \\ Tobâapíra}

Casco da cabeça xe. de. y.

Topete $x e . d e . c$.

\section{Barriga da perna}

\author{
Tetigmã iguê \\ Tetigmã ô̂ \\ Tigmã oô
}


BARROS - O primeiro dicionário médico...

Nos exemplos acima verificamos que os termos indígenas Acangapê e Acangiape têm, ambos, como equivalentes casco da cabeça. Assim, os termos em tupi mantêm uma relação sinonímica entre si, sendo, mais provavelmente parassinônimos, ou seja, termos que possuem uma larga zona de instersecção semântica, mas que não são intercambiáveis em todos os contextos. O mesmo ocorre com os termos Tobâpiába, Tobâapoã, Tobâibíra e Tobâapíra (sinônimos entre si), e os termos Tetigmã iguê, Tetigmã ô̂ e Tigmã oô (idem).. $\mathrm{O}$ primeiro trio tem como equivalente único topete e o segundo, barriga da perna.

Cumpre dizer que o enunciado lexicográfico não traz nenhuma informação explícita que permita fazer uma afirmação categórica sobre este último aspecto, entretanto podemos lançar a hipótese de que a sinonímia possa não ser perfeita por serem os termos variantes não apenas ortográficas, mas de outra natureza e, conseqüentemente, tenham usos de algum modo diferentes. Nossa posição se baseia em informações fornecidas por Ayrosa, grande especialista em línguas indígenas. Segundo esse pesquisador, esses sinônimos constituemse, na verdade, de "variantes de sentido, composições por analogia, regionalismos, etc." (Ayrosa, 1937, p.10).

Graficamente o conjunto de unidades terminológicas que se caracterizam como sinônimos/variantes é, por vezes, reunido por um colchete, como observamos nos exemplos acima. Em outras ocasiões, apresenta-se sob a forma de uma sequiência de termos semelhantes colocados, fisicamente, após o equivalente. É o que ocorre no exemplo abaixo, onde se lê:

\section{2. Ába. Cabello da cabeça. Xeába, deába, yába. (Airosa, 1937, p. 27)}

Nesse verbete, após a entrada em língua de partida (tupi), encontra-se o equivalente em LC (português). Em seguida a este encontram-se as unidades terminológicas xeába, deába, yába. A semelhança formal das mesmas e o tratamento lexicográfico dado a elas evidenciam uma relação sinonímica mantida entre as mesmas. Essas unidades lingüísticas podem ser ou variantes fonético-fonológicas em uso pelos indígenas na época ou expressões adotadas por Castillo para grafar os sons que seus ouvidos podiam captar. Nossa posição apóia-se, mais uma vez, nas explicações de Ayrosa:

\footnotetext{
Si de tal ou qual modo eram ditas e compreendidas certas palavras, assim ele as procurou grafar e traduzir. Nada de preocupações puristas e gramaticais. Retratou o linguajar de sua época e da região em que vivia, com todos seus defeitos e com todos os seus traços característicos. (Ayrosa, 1937 , p. 11)
}

Assim, o registro da sinonímia/variação nos enunciados lexicográficos deve-se a uma preocupação de Castillo em fornecer elementos que facilitassem a compreensão, por parte dos confessores, da língua falada por seus confessados. A variação em si se deve, por outro lado, de acordo com Ayrosa, a particularidades do tupi da região em que se encontrava o autor. Muito provavelmente (hipótese nossa) está ligada a diferenças de falares de grupos indígenas praticantes da mesma língua geral. Nossa posição se apóia ainda na informação contida no próprio título da obra: "\& mais differenças q nelles hâ". Possivelmente predomine no trabalho o tupi tal qual era falado no litoral, já que o dicionário 
Cadernos de Estudos Lingüísticos 46(1) - Jan./Jun. 2004

visava servir de instrumento ao trabalho dos sacerdotes que atuavam na costa nordeste do Brasil.

A sinonímia também se dá em português e, por vezes, é disposta no enunciado lexicográfico de outra forma, como podemos observar abaixo:

145. Perê. Baço ou passarinha. xe. de. y. (Ayrosa, 1937, p. 35)

174. Puçuã âra. Espinhela caída ou derrubada. xe. de. y. (Ayrosa, 1937, p. 36)

179. Sâba. Pello ou cabello do corpo. xe. de. c. (Ayrosa, 1937, p. 37)

Nesses exemplos, os sinônimos dos equivalentes são ligados pela conjunção ou: baço ou passarinha, espinhela caída ou derrubada, pello ou cabello do corpo.

A falta ou o desconhecimento de um termo equivalente preciso em português talvez tenham sido os motivos que levaram o autor a recorrer, em certos casos, a explicações, em lugar de apresentar equivalentes, como podemos observar nos exemplos abaixo:

72. Bopitéraiçâba. Riscos da palma da mão. xe. de. y. (Ayrosa, 1937, p. 31)

102. Iurumopi. Cantos da boca de fora. xe. de. y. (Ayrosa, 1937, p. 32)

128. Moataçâba. $O$ espaço que ha nas costas entre as duas espaduas. xe. (Ayrosa, 1937, p.34)

134. Muruãçáma. A tripa que fica pegada no embigo das crianças qdo. Nac?. xe. de. y. (Ayrosa, 1937, p.34)

137. Muruã porá. Os embigos que sae muyto fora per falta das parteiras. (Ayrosa, 1937, p.35)

181. Tacapê. Espaço que há do embigo até a ventrecha, ou aquella parte assi chamada. xe. de. c. (Ayrosa, 1937, p. 37)

Nesses casos, os enunciados lexicográficos se compõem da entrada em tupi e, no lugar do equivalente, uma paráfrase sinonímica da entrada. Não se trata de uma definição, mas de uma explicação do significado do termo em tupi. Não se pode dizer ao certo se, na época, existiam termos científicos para designar todas essas partes do corpo humano, mas, na terminologia do século XX, riscos da palma da mão são conhecidos, popularmente, como linhas da palma da mão e, cientificamente, como pregas palmares; o que Castillo chamou de cantos da boca de fora tem hoje, como denominação científica, comissuras labiais; o espaço que ha nas costas entre as duas espáduas é designado, atualmente, pelo termo espaço inter-escapular; os embigos que sa? muyto fora per falta das parteiras é conhecido como umbigo protruso; a tripa que fica pegada no embigo das crianças qdo nac? corresponde ao tradicionalmente chamado cordão umbilical, atualmente funículo umbilical (após a Nomina Anatômica de 1997, de São Paulo); o espaço que há do embigo até a ventrecha [nome popular, na época, para barriga], ou aquella parte assi chamada corresponde, hoje, a abdome (Di Dio, 2000, p. 187-190).

Algumas explicações são, porém, de outra natureza, como podemos observar nos exemplos abaixo: 
BARROS - O primeiro dicionário médico...

\section{1. Â. Membri caput. Daqui vem $x e \hat{a}$, meu mano, tomada a metaphora da primeira} significação, e principal. (Ayrosa, 1937, p. 27)

216. Tembê. ..........: ainda que metaphorico he usado. Xe. de. c. (Ayrosa, 1937, p. 39)

Nesses casos, as explicações dadas pelo autor são de tipo metalingüístico, isto é, constituem observações sobre o caráter e uso metafórico dos termos. Poucos são os enunciados lexicográficos que possuem essa característica, mas são um aspecto interessante da obra, uma vez que demonstram uma preocupação do autor em fornecer o máximo possível de informações a respeito do termo, que ultrapassam o objetivo serem úteis no ofício da confissão. Assim, apesar do caráter pragmático da obra e científico da terminologia listada (anatômica), Pero de Castilho teve a preocupação de fornecer também dados metalingüísticos que demonstram uma observação particular da língua e que são comuns nos bons repertórios lexicográficos de hoje.

Com o passar dos séculos, essa obra, considerada por alguns cientistas de nosso tempo como a primeira Nomina Anatomica do Brasil, tornou-se, também, um registro importante do português escrito em nosso país no século XVII.

\section{A PRIMEIRA E A ÚlTimA NOMINA ANATOMICA EM PORTUGUÊS SE ENCONTRAM}

Os professores A.J.C. Bezerra, R.F.A. Bezerra e L.J.A. Di Dio, grandes autoridades brasileiras em Anatomia e terminologia dessa área do saber médico, encantaram-se com a obra de Castillo. Os dois primeiros são professores da Universidade Católica de Brasília e o último, da Universidade de Santo Amaro/Instituto do Coração do Hospital das Clínicas e presidente da Comissão internacional que elaborou a última Nomina Anatômica (de São Paulo), que passou a chamar-se Terminologia Anatômica (FCAT, 2001).

Esses pesquisadores de renome internacional consideram a obra de Castillo como a primeira Nomina brasileira e lhe atribuem grande valor. Para melhor compreendermos essa admiração, é importante conhecer um pouco das características da própria Nomina e sua história, notadamente no que concerne à evolução da terminologia dessa área médica.

\section{A Nomina Anatomica: aspectos históricos}

O processo evolutivo dos estudos no domínio da Anatomia ao longo da história da Humanidade foi acompanhado de um processo lingüístico em constante renovação. Objetivando uma comunicação clara e sem problemas de compreensão em nível internacional, além do estabelecimento de uma classificação geral que garantisse uma uniformidade na descrição dos seres, os cientistas preocuparam-se em criar uma terminologia específica homogênea. Assim, diversas reuniões de comitês especialmente criados para esse fim foram realizadas desde o século XIX e alguns documentos foram elaborados nesse sentido. 
Cadernos de Estudos Lingüísticos 46(1) - Jan./Jun. 2004

A primeira tentativa de homogeneização da terminologia anatômica humana aconteceu em Leipzig, Alemanha, em 1887. A nomenclatura proposta não obteve, no entanto, muito sucesso, sendo pouco seguida. Outra tentativa frustrada foi a da lista proposta por cientistas do Reino Unido e apresentada em 1894. No ano seguinte, nova tentativa foi feita, desta vez com mais sucesso que as precedentes. A Sociedade Alemã de Anatomia propôs a que se convencionou chamar Nomina Anatomica de Basiléia (1895). Esta recebeu adesão total da comunidade científica alemã e tornou-se uma referência importante para diversos países, embora não houvesse ainda unanimidade sobre todas as denominações propostas (Barros, 199, p. 387).

Em 1903 foi fundada a Federação Internacional de Associações de Anatomistas, cujo objetivo maior era o de reunir grupos de anatomistas do mundo todo. Uma de suas principais atribuições era a de analisar os termos designativos das partes do corpo humano então em uso e elaborar uma outra proposta de nomenclatura. Determinou-se que o latim seria a língua do documento e decidiu-se por uma dinâmica de revisão da terminologia a cada cinco anos. Uma importante revisão da Nomina Anatomica de Basiléia foi feita em 1933 pela Sociedade Britânica de Anatomistas, dando lugar à Nomina Anatomica de Birmingham. Em 1935 foi a vez dos alemães procederem a mais uma revisão e de proporem a Nomina Anatomica de Jena. Em 1950, um grupo de cientistas ingleses, reunido em Oxford, começou a preparar nova lista que foi finalmente apresentada em 1955 no Congresso Mundial de Anatomia de Paris: a Nomina Anatomica Parisiensis (Barros, 199, p. 388).

Finalmente, em 1989, a Comissão de Nomenclatura Anatômica da Federação Internacional das Associações de Anatomistas foi livremente eleita pela Assembléia Geral. Compõem essa comissão representantes dos cinco continentes e os critérios para sua escolha foram: serem os melhores especialistas em lingüística anatômica e serem poliglotas com profundos conhecimentos de latim e de grego. O espírito democrático dá à Comissão uma respeitabilidade que pode favorecer a aceitação de sua proposta pela comunidade científica. Seu secretário geral é o médico brasileiro Dr. Liberato John Di Dio. Após oito anos de trabalho, a Comissão apresentou a Nomina Anatomica de São Paulo, em agosto de 1997.

A nova nomenclatura parte da concepção de que não só é necessário que a terminologia médica entre em ritmo de globalização, como também se coloque em consonância com novas dinâmicas de estudos do corpo humano. Um exemplo claro é a perspectiva dos fractais. Criada em 1975 pelo matemático polonês naturalizado americano, Benoit Mandelbrot, a expressão fractal designa uma nova concepção em geometria que ultrapassa a visão tridimensional dos objetos. Segundo essa teoria, estes podem ser analisados em dimensões fracionárias. Assim, qualquer objeto, inclusive as partes do corpo humano, poderiam ser vistas, por exemplo, em três dimensões e meia. Esta teoria já tem sido aplicada nos estudos do fígado pelo próprio Dr. Liberato Di Dio e acredita-se que em breve começará a ser aplicada ao estudo de todos os órgãos da máquina humana. Surgirão, então, novas partes, pois o corpo humano será visto de modo diferente (Barros, 199, p. 388).

O processo de revisão e de apresentação de novas propostas de nomenclatura nessa área tem sido longo e constante. O objetivo de se uniformizar em nível internacional a terminologia designativa das estruturas do corpo humano ainda não foi totalmente atingido. 
BARROS - O primeiro dicionário médico...

\section{A Nomina Anatomica de São Paulo e a Criação de neônimos}

Redigida em latim e em inglês, a nova terminologia anatômica foi traduzida para o português e publicada em 2001. No total, cerca de 10 mil termos foram revistos. Desses, quatro mil não foram considerados pertinentes e, portanto, somente seis mil foram efetivamente analisados. O princípio orientador da nova nomenclatura foi o de consagrar o uso de termos mais precisos, informativos, descritivos e simples, além de desambigüizar a terminologia (Barros, 199, p. 389).

Um dos problemas atacados pela Nomina de São Paulo foi o de designações pouco informativas quanto à forma ou função da estrutura anatômica em questão. Uma expressão desse tipo de problema são os epônimos, como por exemplo, trompa de Eustáquio e tendão de Aquiles. Os nomes próprios Eustáquio ou Aquiles pouco ou nada diziam a quem não conhecesse a origem do termo. Os cientistas preferem, então, substituí-los respectivamente pelos termos trompa auditiva e tendão calcâneo. No primeiro caso, o termo complexo torna-se mais carregado de significação e marcado por semas aplicativos que indicam a função da trompa. No que se refere a tendão calcâneo, o qualificativo ressalta a localização do referido tendão (calcanhar). $\mathrm{O}$ mesmo acontece com o epônimo trompa de Falópio, agora chamado tuba uterina.

Havia ainda problemas de polissemia, quando um mesmo termo designava estruturas diferentes. Um exemplo é o termo cúbito. Este designava anteriormente: 1) o osso longo que, junto com o rádio, formava o antebraço; 2) o cotovelo. Para se eliminar o problema de imprecisão e/ou polissemia desse termo, decidiu-se chamar ulna o osso longo que, com o rádio, forma o antebraço e cúbito o antigo cotovelo.

O problema da imprecisão terminológica tinha, por vezes, origem em uma lacuna científica. Um exemplo é o caso do termo corpo pineal. Até pouco tempo não se sabia ao certo como classificar esse "corpo" do ponto de vista anatômico. Recentemente descobriuse que se trata de uma glândula. A Nomina Anatomica de São Paulo propõe, então, que corpo pineal seja substituído por glândula pineal (Barros, 199, p. 390).

A nova nomenclatura procura ainda corrigir a expressão de erros lógicos em Anatomia, como por exemplo, o termo pomo de Adão. Segundo o Dr. Liberato Di Dio, a referência a Adão (que, em hebraico, significa "homem") é errônea, pois há mulheres que apresentam essa protuberância, enquanto que alguns homens não a apresentam. A referência a Adão ou a Eva (que, em hebraico, significa "mulher") é, portanto, incorreta. Para corrigir esse erro lógico e propor um termo mais neutro e carregado de informação, adotou-se o termo proeminência laríngea.

Havia, enfim, diversos outros tipos de problemas, tais como parassinonímia entre termos complexos e simples. Nesses casos, a Nomina de São Paulo procura seguir o princípio da biunivocidade (ou monossemia), ou seja, atribuir uma única designação à estrutura anatômica. Deu também preferência ao uso de termos simples em relação a parassinônimos complexos (Barros, 199, p. 390).

A primeira e a última Nomina Anatomica em português se encontram

A Nomina Anatômica constitui, portanto, um valioso instrumento de harmonização terminológica no domínio da Medicina. Os professores A.J.C. Bezerra, R.F.A. Bezerra e L.J.A. Di Dio, conhecedores que são de sua importância, não puderam deixar de admirar 
Cadernos de Estudos Lingüísticos 46(1) - Jan./Jun. 2004

a obra de Castillo e aliaram seus conhecimentos especializados em Anatomia e aos sobre sua terminologia para dar um novo tratamento aos dados registrados pelo padre do século XVII. O trabalho de reelaboração dos Nomes das partes do corpo... produziu o seguinte resultado (Di Dio, 2000, p. 187-190):

$\hat{\mathbf{A}}=$ Membri caput (glande). Cabeça do membro viril. A palavra caput, além de cabeça, também pode significar bola, grão, semente.

Acaiâ = Matrix in foeminis (útero). Enquanto no Dicionário BrasilianoPortuguês o termo é traduzido como "madre das mulheres", no Vocabulário de Piratininga aparece como "madre da molher ou de qualquer femea".

Acangapê $=$ Casco da cabeça (calota craniana). A palavra deriva de acánga, mais pê, que significa casca, crosta. É interessante observar que api é couro cabeludo. Cui é pó. Caspa é apicui.

Aceôpiáýa = Padar (palato). Piá parece ser corruptela de piaguá que pode ser traduzido por côncavo (céu da boca).

Agueâ $=$ Dentes queixaes (dentes molares). Nas aves têm o significado de moela (que moe).

Aiûra $=$ Pescoço . Esta palavra parece resultar da união do termo guarani (ayú) e do tupi (ajúra).

Âmopîra = coxa pella parte morta das nadegas (face posterior da extremidade proximal da coxa). Añã significa grossa (aqui no sentido de glúteos) e guîra o que
Ába = Cabello da cabeça (cabelo). Por abebô entende-se cabelo grande, cabeludo. Amotâba é bigode. Buço é apoãâba.

Acánga = Cabeça . O prefixo "a" significa cabeça e "cang" significa duro. Assim acánga deve ser traduzido, com mais exatidão, como crânio.

Aceôca $=$ Garganta. Nos peixes têm o significado de guelras. Em outros animais goela ou papo. Aceôcáýa = Campainha (úvula). Áýa significa pendente, suspenso.

Açû = Mão esquerda. Deve ser a maneira coloquial de poaçû. Açû é grosseiro ou seja, poaçû é a mão sem destreza. Ecatuâba é a mão direita. Deriva de écatú (hábil, jeitoso, apto).

Aipi $=$ Cacho do pescoço (proeminência larín-gea). Api é saliência e ayê significa coisa arredon-dada.

Âjurû = Canalis membri (uretra peniana). Jurû ou iurû é boca no sentido de entrada ou do início do tubo digestório. Canal do membro (viril). O termo melhor define o óstio externo da uretra ou do meato urinário. Nesta oportunidade registre-se que o canto da boca é iurû ou iurupopi.

Apecu = Língua. No sentido mais amplo é tudo que é achatado e comprido. Apecu apira é a ponta ou ápice da língua. 
BARROS - O primeiro dicionário médico...

fica localizado logo abaixo ou a coxa depois que morre a nádega

Apiçâ = Ouvidos (orelhas). Desta deriva apî-çáy (surdo). Namby é o pavilhão auricular (da orelha externa) e apiçâcoâra é o meato acústico externo. Cerume é apiçâcoaruuma.

Apîra = Moleira (fontanela, fontículo). O sig-nificado geral é ápice, cume.

Aputuuma $=$ Miolos. Deriva de pituu que quer dizer recheio mole (cérebro). Pode ser também miolo de pão e juízo no sentido figurado. Aputu-umaôba significa saco dos miolos (meninges). Talvez medula dos ossos (tutano) e, por extensão, a medula da coluna vertebral, que os antigos consideravam um só osso longo, e que atualmente é a medula espinhal.

Atîba $=$ Fontes (têmporas). Atibaiá são os cabelos das têmporas (costeletas).

Atucupê = As costas. Escápula chama-se iibâpecãga.

Biâ = Fígado. Biâupiâra é fel (bile).

Bîra $=$ Pelle. Tegumento.

Bopitâ $=$ Punho.

Câba $=$ Gordura (tecido adiposo). Tela subcutânea.

Cuâ = Cintura.

Apijguára = Cachagens (conchas nasais). Deriva de apijã (narinas). Apijguarába são os pêlos do nariz (vibrissas).

Apoã = Beiço de cima (lábio superior). $\mathrm{O}$ lábio inferior é tembê.

Arucánga $=$ Costelas. Arucangira é cartilagem costal. Arucanguíra é o "vão das costellas debaixo" (espaço intercostal).

Atiîba $=$ Hombro (ombro). Região da espádua.

Bi = Pee (pé). Biçâ é dedo do pé, na forma guarani. Na forma tupi é picú.

Bicupê = Peito do pee. É o dorso do pé. Bipitéra é a "sola do pee" (planta).

Bô = Mão. Bocupê ou pócupê significa costas da mão (dorso da mão). O oposto, palma da mão é popitê ou bopitéra.

Bopitéicâba = Riscos da palma da mão (Pre-gas palmares, linhas da palma da mão). Bopitéraiçâba é sinônimo.

Câma = Peito, teta. Câma apoã é a ponta da teta (papila mamária, paoila da mama, mamilo). Canga $=$ Osso. Serve para osso em pessoa viva. $\mathrm{O}$ osso em um esqueleto (ossada) é canguêra.

Ieapaçâba = Curua do giolho (patela). 
Cadernos de Estudos Lingüísticos 46(1) - Jan./Jun. 2004

Iepotaçâba = Iuntas (articulação).

Iibâipi = Aarreigada do braço (ombro).

Ibiyã $=$ Entranhas (tripas, vísceras ou órgãos viscerais).

Iurumopê $=$ Cantos da boca de fora (comissuras labiais).

Miçã = Dedo do pee. Qualquer dedo do pé.

Miçã guaçû = Dedo polegar do pee. Guaçu é grosso. Dedão. (Halux ou grande dedo do pé).

Miçã mirî = Dedo memingo do pee. Minguinho (dedo mínimo). Ver Moã miri.

Miçãpê = Unha do dedo do pee. Apê é a unha.

Mitâ = Calcanhar. Calcâneo.
Iibâ = Braço. Iibâcánga é a cana do braço (úmero). Iibâguîra é sobaco (sovaco, axila) visto que guî significa embaixo. Iibâguirâba são os pêlos da axila ou hircos.

Iibaipiaiýa = Lagarto do braço (bíceps do braço). Para os músculos do compartimento ante-rior do braço usa-se também o termo iibâtupôyá (bucho do braço). Obviamente tem o sentido de ventre muscular. Músculo (diminutivo de $m u s$, rato) do braço é o ratinho do braço, ou seja, o pequeno rato do braço.

Iurû $=$ Boca . Iurubôca $=$ Abertura da boca (rima oris ou rima da boca).Também significa fenda, rachadura.

Membinhemonhãgâba $=$ Matrix in foemi-nis. O sentido é de lugar onde se gera o filho pois membir significa filho. $\mathrm{O}$ uso da palavra membir é privativa das mulheres da tribo. (Ver acaiâ).

Miçã apira = A ponta de dedo do pee Apira é bico, ponta.

Miçã guaçû Ibirixoâra $=$ Dedo do pee junto ao polegar. Deriva de ibirichuar que significa vizinho.

Miçã mitêra $=$ Dedo do meyo. Deriva de pítera (meio).

Miçãquitâ $=$ Noos dos dedos dos pees. Quitã é nó, caroço, verruga. Poderia ser nós dos dedos, ao nível das articulações das falanges.

Miteribirixoâra $=$ Dedo que está junto ao dedo do meyo. Provavelmente subentendese que esta palavra é precedida de miçã (dedo), pois seu significado literal é vizinho do meio. 
BARROS - O primeiro dicionário médico...

Moã = Dedo da mão. Moãguaçû significa dedo grosso da mão.

Moã miri $=$ Dedo memingo da mão $($ dedo mínimo).

Moã miter ibirixoâra $=\mathbf{O}$ quarto dedo da mão (dedo anular).

Moãpira $=$ Ponta dos dedos das mãos.

Moataçâba $=0$ espaço que ha nas costas entre as duas espaduas. Moatár é distante e hába é o lugar. Deve ser o lugar que não se alcança com a mão. Espaço interescapular.

Muçuã = Espinhela (processo xifóide). $\mathrm{O}$ que se mexe, balança. Muçuã apira é a ponta da "espinhela".

Muruãçáma $=$ A tripa que fica pegada no embigo das crianças quando nace (cordão umbilical, atualmente o funículo umbilical). Çama é corda. Funículo é pequena corda, cordinha.

Nambi = Orelha. Pode ser alça, aba. É orelha por semelhança.

Penarãga $=$ Rodella do giolho . Rótula (rodinha) do joelho. Hoje, patela.

Pî̀ = Pee. Também é pé de mesa.

Piçã = Dedo do pee. Picupê é o peito do pé.
Moã iepotaçâba $=$ Junturas dos dedos da mão.

Moã mitêra $=$ Dedo do meo da mão $($ dedo médio).

Moape $=$ Unhas da mão

Moãquitã = Os noos dos dedos das mãos . É mais utilizado no sentido das cabeças dos ossos do metacarpo.

Motiâ $=$ Peitos. Do pescosso até o vasio (Parede anterior do tórax). Peito sem ser no sentido de mama. Motiââba são os pêlos do peito.

Muruã = Embigo (umbigo). Mi ou mu pi significa centro e huã talo.

Muruã pôra = Os embigos que sae muyto fora per falta das parteiras (umbigo protruso). Pôra é saltar, pular. É interessante $a$ atribuição de culpa às parteiras (não havia médicos? obstetras).

Nhiã = Coraçam (coração). Pode ser usada como vísceras. A pronúncia neã talvez designe mais precisamente coração. Nhiãbebúya ("bofes") tem o sufixo búya que significa que bôia, flutua. Talvez pulmões. Nhiãçáma (cordas do coraçam) são as cordas tendíneas visto que o sufixo isoladamente é fibra, corda.

Perê = Baço ou passarinha

Piâ = Figado. Parece ser víscera de uma maneira geral. Piâupiâra significa fel (bile).

Pipitêra é a sola do pé. 
Pira $=$ Pelle.

Pita $=$ Calcanhar. Calcâneo.

Pô = Mão. Ver também bô. Poã é dedo da mão. Poãbeigâba significa dedo indicador ou índice, index (mais precisamente é apontar com o dedo). Pobobôca ou pópitêjcâba quer dizer riscos (linhas) da palma da mão (pregas palmares).

Puçuã = Espinhela. Ver muçuã (processo xifoide, do esterno).

Puruã = Embigo. Ver muruã.

Sibâ $=$ Testa. Fronte.

Tacô $=$ Uirilha. Também quadris, ancas ou cadeiras, em ambos os sexos. Região inguinal.

Tacoayipitã âba $=$ Pubes in maribus . Devia ser pubes in viri (pube do homem, do marido).

\section{Táya $=$ Dentes}

Taibira $=$ Gengiuas. $\mathrm{Na}$ verdade pira ou bira é pele ou couro. Táiioâra é o alvéolo dental.

Tapiâ $=$ Testiculi, saculus. Também apiá. (Testículos, sáculo, pequeno saco, escroto, onde estão situados os testículos).

Tapupê $=$ Partes extera utrinque (vulva).

Teça $=$ Olho
Piriquitic $=$ Rim.

Pitangurû = Matrix in foeminis. Pitang é criancinha. Urû deriva de rerú, criança, filho. Seu equivalente é pitangnhemonhãgâba (útero).

Popitêra = Palma da mão. Pócupê significa costas da mão (dorso da mão).

Puraq $=$ Cotouello. Atualmente, região posterior do cúbito.

Sâba $=$ Cabello do corpo, pello.

Tacapê = Espaço do embigo até a ventrecha (abdome). Ventrecha é barriga no popular. Ventre.

Tacoâba $=$ Pubes in foeminis. Monte púbico feminino, onde se encontra os pêlos (púbios). Região púbica da mulher.

Tacoaýa = Genitale viri. Aquãi é ponta, alongado. (órgão genital externo do homem, pênis). Observe-se que Uûba é genitale viri (genital do homem) do ponto de vista metafórico, de uib flexa, haste, caniço, vara.

Táimitêra $=$ Dentes dianteiros (incisivos).

Tapiâçãma $=$ As cordas do testiculi (funículo espermático).

Tapupîiurû = Os vagis (óstio vaginal). Iurû é boca, entrada.

Teçâ̂ra $=$ Minina do olho (pupila) . 
BARROS - O primeiro dicionário médico...

Teça obi $=$ Bilida. Obi é verde ou azul. Faz alusão à íris.

Tebîra = Nadegas. Tebi, ebi também significam nádegas. Glúteos, região glútea.

Tembê = Beiço embê é labio inferior.

Tendibâ = Barba, parte per onde soe nacer (queixo, mento).

Tendipiã = Joelho ou tenypiã.

Tetimã $=$ Perna ou timã $=$ perna .

Tetimã iguâ = Barriga da perna (panturrilha) ou tetimã oô ou timãoô.

Tetobapê $=$ Face . Na verdade na frase tem sentido de bochecha.

Tiquê = Barriga, $\mathbf{o}$ interior $($ cavidade abdominal).

Tiurû = Bexiga ou irû. Irû é recipiente, conti-nente, vaso, depósito, bexiga urinária.

Tobâ = Rosto humano (face, cara).

Topeâba = Pestanas (cílios). Literalmente cabelo (âba) da pálpebra.

Ûba $=$ Coxa da parte dianteira (coxa). Face anterior da coxa.

Ûba poã aiýa = Lagarto (ventre muscular). Lagarto é toda parte muscular polpuda, carnuda dos membros inferiores. Ver Iibaipiaiýa.
Teçâ tinga = Bilida. Tinga é branco (esclera). Belida significa mancha esbranquiçada na córnea.

Teicoâra $=$ Podex (intestino reto, ânus). Tei deriva de tebî, assento e coára orifício, buraco.

Tenangupi $=$ Quadril ou Tumbi $=$ cadeiras (quadril), ancas.

Puraq, tendibagã ou tenybangâ = Cotovelo (cotovelo, esquina, ângulo). Região cubital, cúbito.

Tetê $=$ Corpo humano.

Tetimã canga $=$ Canella da perna (tíbia)

Tetimã iûra $=$ Collo da perna (tornozelo) .

Te = Nariz. É ponta, bico . Tiápira é a ponta do nariz.

Tiguê poî = Tripas (intestino delgado, órgãos viscerais). Poî é fibra, filamento, fio, cordão.

Toô = Carne humana (músculo). Oô é carnudo, encorpado.

Topê = Capella dos olhos (órbita e pálpebra). Bainha, vagem.

Tumbiquira $=$ Rabadilha ( (óccix). Deriva de tumbiquir que significa ápice, ponta, rabo, cauda.

Ûba poã = Ponta da coxa junto ao giolho (extremidade distal da coxa). 
Cadernos de Estudos Lingüísticos 46(1) - Jan./Jun. 2004

Como podemos observar, aos termos originais em tupi descritos nos verbetes dos Nomes das partes do corpo.... e seus equivalentes em português foram acrescentadas as atuais denominações das estruturas anatômicas Aliás, percebe-se no dicionário resultante do trabalho dos pesquisadores a presença de termos não apenas utilizados no século XX, mas também os mais recentemente adotados pela Terminologia Anatômica, publicada no Brasil em 2001. É o caso, por exemplo, de:

Mitâ = Calcanhar. $\underline{\text { Calcâneo }}$.

Sibâ = Testa. Fronte.

Aipi = Cacho do pescoço (proeminência laríngea)

Assim, os enunciados lexicográficos foram enriquecidos com comentários de caráter metalingüístico, enciclopédico e da especialidade da Anatomia. O trabalho dos professores aproximou o que eles próprios consideram como a primeira Nomina Anatômica do Brasil da última versão desta. O interesse desses especialistas por uma obra do século XVII evidencia o prestígio e o respeito que o trabalho de Castillo angariou ao longo da história da Medicina e ainda mantém 400 anos depois de sua elaboração.

\section{CONCLUSÃO}

O vocabulário bilíngüe de Pero de Castilho tornou-se uma referência para os estudos lingüísticos do tupi e do português coloniais e deu uma contribuição ao resgate da história da Anatomia e da Medicina no Brasil. Os Nomes das partes do corpo... podem ser considerados, como já nos pronunciamos, como o primeiro dicionário de área médica de nosso país e como a primeira Nomina Anatômica nacional.

Por seus objetivos e público-alvo fica claro que a obra tinha a intenção de servir como instrumento de trabalho a padres em seu exercício de confissão na região nordeste do Brasil, junto aos silvícolas. Para tanto, foi organizada em forma de dicionário bilíngüe, composto de duas partes: tupi-português e vice-versa. O modelo de microestrutura prevê alguns dados constantes, a saber: a entrada e seu equivalente. Dados metalingüísticos relativos ao uso de pronomes e à variação terminológica (lexical) não são constantes, sendo apresentados de acordo com a existência e/ou necessidade dos mesmos.

É evidente que o tratamento da nomenclatura não se fundamenta em nenhum modelo teórico da Lexicografia, mas nem por isso a obra de Pero de Castillo deixa de se caracterizar como um dicionário médico bilíngüe, visto suas características intrínsecas, que o situam, dentro de uma tipologia geral de obras, dentro de padrões de identificação de um dicionário. De acordo com os dados que possuímos até o momento, provenientes de nossa pesquisa sobre a história dos dicionários médicos no Brasil, este assume o estatuto de primeiro dicionário de uma área médica feito por brasileiro e publicado em nosso país. 
BARROS - O primeiro dicionário médico...

\section{REFERÊNCIAS BIBLIOGRÁFICAS}

AYROSA, Plinio. (1937). Os Nomes das partes do corpo humano pella lingua do Brasil, de Pero de Castilho. Texto tupi-português e português-tupi do seculo XVII. São Paulo: Empresa Gráfica da Revista dos Tribunais.

BARROS, Lidia Almeida. (1999). Aspectos da dinâmica lexical no domínio da Medicina: a Nomina Anatomica. Estudos Lingüisticos, São Paulo, v. 28, p. 385-390.

DI DIO, L.J.A.; A.J.C. BEZERRA \& R.F.A. BEZERRA. (2000). Brasil 500 anos. Nomenclatura anatômica de um jesuíta no tempo do Descobrimento. Rev Ass Med Brasil, 46(2): 186-90 186.

FEDERATIVE COMMITTEE ON ANATOMICAL TERMINOLOGY. (2001). Terminologia Anatômica Internacional. São Paulo: Manole.

NUNES, José Horta. (1996). Discurso e instrumentos lingüísticos no Brasil: dos relatos de viajantes aos primeiros dicionários. Tese defendida na Universidade Estadual de Campinas-UNICAMP. 